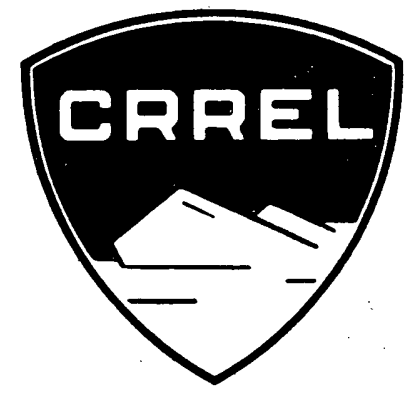

Research Report 217

\title{
A NEW SOLUTION OF \\ THE BOUNDARY LAYER EQUATION AND ITS APPLICATION \\ by
}

Fuat Odar

AUGUST 1967

U.S. ARMY MATERIEL COMMAND

COLD REGIONS RESEARCH \& ENGINEERING LABORATORY HANOVER, NEW HAMPSHIRE

DA Task IV014501B 52 A02

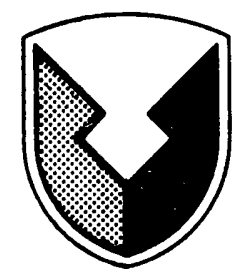




\section{PREF ACE}

This paper was prepared by Dr. Fuat. Odar, Research Physical Scientist, of the Research Division (James A. Bender, Chief), U. S. Army Cold Regions Research and Engineering Laboratory.

The assistance rendered by SP Don P. Forgey in computer program-, ming and computation of the integrals is gratefully acknowledged.

USA CRREL is an Army Materiel Command laboratory. 


\section{Errata - Research Report 217}

Page 9, eq 38: for $a \frac{j+4}{2}$ read $a^{\frac{j+4}{2}}$

Page 10, line above eq 42: for $u_{1 i}$ read $u_{1 i}$

Page 10, eq 42: for $\sum_{0}^{n} \operatorname{read} \sum_{0}^{5}$

Page 14, line 4: for $t^{j+2 / 2} \operatorname{read} t^{(j+2) / 2}$ 
CONTENTS

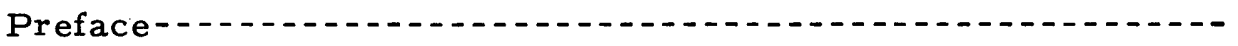

Summary - List of symbols

Introduction - - -

Solution of the approximation terms-

Skin friction----10

Application -

Page

ii

iv

$\mathrm{v}$

Conclusion -

Literature cited

Appendix A-

Appendix B-1...

Appendix $\mathrm{C}$ : Values of $\mathrm{C}_{\mathrm{ni}}$

20

\section{ILLUSTRATIONS}

Figure

1. Comparison of $g_{1}(\eta)$ with Blasius' $\left(\frac{1}{2} \pi^{\frac{1}{2}} \zeta_{3}{ }^{\prime}\right)$ function --..- 


\section{SUMMARY}

Solutions of the boundary layer equation for an unsteady flow have previously been obtained for only a few boundary conditions such as those which exist in suddenly accelerated or uniformly accelerating flows. In this paper a general solution using the method of successive approximations for an arbitrarily accelerating flow is presented. The solution, which is expressed in an integral form including the acceleration as a chosen function of time, is valid for both two-dimensional and axially symmetrical flows.

In order to show the feasibility of the solution one example is presented where

$$
U=\left(a_{1} t+a_{2} t^{2}+a_{3} t^{3}+a_{4} t^{4}\right) h(x)
$$

i. e., the variation of velocity outside of the boundary layer is a fourth degree polynomial in time multiplied by a function $h(x)$. 


\section{LIST OF SYMBOLS}

$\begin{array}{ll}\mathbf{a} & =\text { acceleration outside boundary layer } \\ \mathbf{h}(\mathbf{x}) & =\text { function depending on shape of object } \\ \mathbf{L} & =\text { linear operator independent of } t \\ \mathbf{r}(\mathbf{x}) & =\text { function depending on shape of object } \\ \mathbf{t} & =\text { time } \\ \mathbf{U} & =\text { velocity outside boundary layer } \\ \mathbf{u}_{\mathbf{i}} & =\text { Fourier sine transform of } \mathbf{u}_{\mathbf{i}} \\ \mathbf{u} & =\text { velocity component of fluid in } \mathbf{x} \text { direction } \\ \mathbf{v} & =\text { velocity component of fluid in y direction } \\ \eta_{\mathbf{i}} & =\text { boundary layer thickness as defined } \\ \boldsymbol{\tau} & =\text { shear stress } \\ \boldsymbol{\mu} & =\text { dynamic viscosity } \\ \boldsymbol{v} & =\text { kinematic viscosity }\end{array}$




\section{A NEW SOLUTION OF THE BOUNDARY LAYER EQUATION \\ AND ITS APPLICATION}

by

Fuat Odar

\section{INTRODUC TION}

The boundary layer and continuity equations for a two-dimensional flow in the absence of sharp corners are

$$
\frac{\partial u}{\partial t}+u \frac{\partial u}{\partial x}+v \frac{\partial u}{\partial y}=\frac{\partial U}{\partial t}+U \frac{\partial U}{\partial x}+v \frac{\partial^{2} u}{\partial y^{2}}
$$

and

$$
\frac{\partial u}{\partial x}+\frac{\partial v}{\partial y}=0
$$

in which $u$ and $v$ are the velocity components of the fluid in the $\mathrm{x}$ and $\mathrm{y}$ directions and $v$ is the kinematic viscosity. These equations are to be solved for appropriate boundary conditions. Heretofore, no exact solution has been obtained because of the extreme difficulty of solving the nonlinear boundary layer equation. Generally, a researcher finds that he must be satisfied with a solution involving successive approximations. A conventional method is outlined as follows:

(a) Assume that the velocities are the sum of some approximation terms

$$
\mathrm{u}=\mathrm{u}_{0}+\mathrm{u}_{1}+\mathrm{u}_{2}+\ldots, \quad \mathrm{v}=\mathrm{v}_{0}+\mathrm{v}_{1}+\mathrm{v}_{2}+\ldots
$$

(b) Determine the values of these approximation terms consecutively from the following differential equations.

$$
\begin{aligned}
& \frac{\partial u_{i}}{\partial t}-v \frac{\partial^{2} u_{i}}{\partial y^{2}}=f_{i}(x, y, t), \quad i=0,1,2 \ldots \\
& \frac{\partial u_{i}}{\partial x}+\frac{\partial v i}{\partial y}=0, \quad i=0,1,2 \ldots
\end{aligned}
$$

in which

$$
\begin{aligned}
& f_{0}=\frac{\partial U}{\partial t} \\
& f_{1}=U \frac{\partial U}{\partial x}-u_{0} \frac{\partial u_{0}}{\partial x}-v_{0} \frac{\partial u_{0}}{\partial y} \\
& f_{2}=-u_{0} \frac{\partial u_{1}}{\partial x}-u_{1} \frac{\partial u_{0}}{\partial x}-v_{0} \frac{\partial u_{1}}{\partial y}-v_{1} \frac{\partial u_{0}}{\partial y}
\end{aligned}
$$

Further expressions for the functions $f_{i}$ can be developed when higher order approximation is required. The boundary conditions are

$$
u_{0}(x, 0, t)=0, \quad u_{0}(x, \infty, t)=U(x, t), \quad u_{0}(x, y, 0)=0
$$

and 


$$
u_{i}(x, 0, t)=0, \quad u_{i}(x, \infty, t)=0, \quad u_{i}(x, y, 0)=0
$$

for $i=1,2,3 \ldots$

If the nonlinear (convective acceleration) terms in eq 1 are small compared to the other terms, satisfactory answers may be obtained by calculating the first two or three approximation terms. This may be the case if there is a rapidly accelerating flow where $\nu \frac{\partial^{2} u}{\partial y^{2}}$ and $\frac{\partial U}{\partial t}$ are large. Otherwise, the calculation of higher order approximation terms may be necessary to obtain the desired accuracy.

Solutions of the approximation terms have been obtained only for a very limited number of problems. One of them is the case of a sudden acceleration of a body starting at rest and moving at a constant velocity the reafter. In this case $f_{0}=0$ for $t<0$ and $f_{0}=U(x)$ for $t>0$. The solution for $u_{0}$ is given in many of the standard textbooks on boundary layer theory (e.g., Schlichting, 1960). The solutions for $u_{1}$ and $u_{2}$ were obtained by Blasius (1908) and Goldstein and Rosenhead (1936), respectively.

Another problem is the case of a uniform acceleration of a body which was initially at rest. The solutions for $u_{0}, u_{1}$ and $u_{2}$ for this case were obtained by Blasius (1908). More complicated cases involving some nonlinear accelerations, where $U=h(x) t^{n}$ with $n=0,1,2,3,4$, were studied by Goertler (1944). Recently Watson (1955) extended the work of Blasius to the cases where $U(t)=A t^{a}$ and $\mathrm{U}(\mathrm{t})=\mathrm{Ae} \mathrm{e}^{\mathrm{ct}}$.

In all the problems mentioned above the flow around the body was two-dimensional. Boltze (1908) applied the method of successive approximations to solve problems where the flow is axially symmetrical. In this case the boundary layer equation remains in the same form but $x$ and $y$ are the curvilinear coordinates parallel and normal respectively to the surface of the body. The equation of continuity changes to

$$
\frac{\partial(\mathrm{ur})}{\partial \mathrm{x}}+\frac{\partial(\mathrm{vr})}{\partial \mathrm{y}}=0
$$

in which $r(x)$ is the variable radius which specifies the contour of the body. of revolution. Thus, the continuity equation for the approximation terms is

$$
\frac{\partial\left(u_{i} r\right)}{\partial x}+\frac{\partial\left(v_{i} r\right)}{\partial y}=0
$$

which should be considered instead of eq 5 in solving the problem of an axially symmetrical boundary layer. To the writer's knowledge, solutions for the first three approximation terms in an axially symmetrical flow have been obtained only for the case of a sudden acceleration by Boltze (1908).

The writer has solved eq 4 for an arbitrary function and for an arbitrary boundary condition, namely an arbitrary $U(x, t)$. The only limitation is that the fluid should be initially at rest. The solution is valid for both two-dimensional and axially symmetrical boundary layers. 


\section{SOLUTION OF THE APPROXIMATION TERMS}

Before presenting the solution of the first approximation term it is necessary to give some background information. Consider a linear differential equation of the type

$$
L u=\frac{\partial u}{\partial t}
$$

in which $L$ is a linear operator independent of $t$. Let $g(x, t)$ be a solution of this differential equation. If $g(x, 0)=0$, then $\int_{0}^{t} F\left(t-t^{\prime}\right) g\left(x, t^{\prime}\right) d t^{\prime}$ is also a solution. This may be proved as follows:

Let $t-t^{\prime}=t^{\prime \prime}$. The integral solution becomes $\int_{0}^{t} F\left(t^{\prime \prime}\right) g\left(x, t-t^{\prime \prime}\right) d t^{\prime \prime}$. If the derivative with respect to $t$ is taken,

$$
\frac{\partial}{\partial t} \int_{0}^{t} F\left(t^{\prime \prime}\right) g\left(x, t-t^{\prime \prime}\right) d t^{\prime \prime}=\int_{0}^{t} F\left(t^{\prime \prime}\right) \frac{\partial g\left(x_{p} t-t^{\prime \prime}\right)}{\partial t} d t^{\prime \prime}+F(t) g(x, 0)
$$

can be obtained. The last term is zero since $g(x, 0)=0$. Since $g(x, t)$ is a solution of eq 10

$$
\begin{aligned}
\int_{0}^{t} F\left(t^{\prime \prime}\right) \frac{\partial g\left(x, t-t^{\prime \prime}\right)}{\partial t} d t^{\prime \prime} & =\int_{0}^{t} F\left(t^{\prime \prime}\right) L g\left(x, t-t^{\prime \prime}\right) d t^{\prime \prime} \\
& =L \int_{0}^{t} F\left(t^{\prime \prime}\right) g\left(x, t-t^{\prime \prime}\right) d t^{\prime \prime}
\end{aligned}
$$

The stated result follows immediately. These integral solutions were used by Basset (1888) to solve the problem of an accelerating sphere in a fluid. They are also widely used in heat conduction problems. The function $F\left(t-t^{\prime}\right)$ is determined from the boundary conditions.

Now the problem of the unsteady fluid flow caused by an arbitrary and rectilinear motion of an infinitely long flat plate will be investigated. The Navier-Stokes equations reduce to

$$
\frac{\partial u}{\partial t}=v \frac{\partial^{2} u}{\partial y^{2}}
$$

in which $\mathbf{u}$ is the velocity parallel to the plate. If the plate is accelerated suddenly from rest and its velocity is kept at unity thereafter, the boundary conditions are $u(y, 0)=0, u(0, t)=1$ and $u(\infty, t)=0$. The solution which can be found in many standard textbooks (e.g, Schlichting, 1962) is .

$$
u=1-\operatorname{erf} \eta
$$


where $\eta=\frac{1}{2} y(v t)^{-\frac{1}{2}}$. For an arbitrary acceleration the boundary conditions are $\mathrm{u}(\mathrm{y}, 0)=0, \mathrm{u}(0, \mathrm{t})=\mathrm{U}(\mathrm{t})$ and $\mathrm{u}(\infty, \mathrm{t})=0$. The integral solution is

$$
u(y, t)=\int_{0}^{t} F\left(t-t^{\prime}\right)\left[1-\operatorname{erf} \eta^{\prime}\right] d t^{\prime}
$$

where $\eta^{\prime}=\frac{1}{2} y\left(\nu t^{\prime}\right)^{-\frac{1}{2}}$. According to the second boundary condition,

$$
u(0, t)=\int_{0}^{t} F\left(t-t^{\prime}\right) d t^{\prime}=U(t) .
$$

Thus,

$$
F(t)=\frac{\partial U}{\partial t}=a(t)
$$

where $a$ is the acceleration. The solution becomes

$$
u(y, t)=\int_{0}^{t}\left(1-\operatorname{erf} \eta^{\prime}\right) a\left(t-t^{\prime}\right) d t^{\prime}
$$

whe re

$$
\operatorname{erf} \eta^{\prime}=2 \pi^{-\frac{1}{2}} \int_{0}^{\eta^{\prime}} e^{-z^{2}} d z
$$

This result will be used to obtain the solution of the first approximation term. The differential equation for the first approximation term is

$$
\frac{\partial \mathrm{u}_{0}}{\partial \mathrm{t}}-v \frac{\partial^{2} \mathrm{u}_{0}}{\partial \mathrm{y}^{2}}=\frac{\partial \mathrm{U}}{\partial \mathrm{t}}
$$

and the boundary conditions are $u_{0}(x, 0, t)=0, u_{0}(x, \infty, t)=U(x, t)$ and $u_{0}(x, y, 0)=0$. By introducing a new variable, $u_{0}^{\prime}(x, y, t)=u_{0}(x, y, t)-U(x, t)$, this differential equation reduces to

$$
\frac{\partial u_{0}^{\prime}}{\partial t}-v \frac{\partial^{2} u_{0}^{\prime}}{\partial y^{2}}=0
$$

and the boundary conditions change to $u_{0}{ }^{\prime}(x, 0, t)=-U(x, t), \quad u_{0}{ }^{\prime}(x, \infty, t)=0$ and $\mathrm{u}_{0}{ }^{\prime}(\mathrm{x}, \mathrm{y}, 0)=0$. Note that $\mathrm{U}(\mathrm{x}, 0)=0$.

Equations 11 and 15 and their boundary conditions are the same except that the second boundary condition of eq 15 has a minus sign. Thus the solution for the first approximation term can be readily obtained in the form

$$
u_{0}=\int_{0}^{t} \frac{\partial U}{\partial t^{\prime \prime}} \operatorname{erf} \frac{1}{2} y\left[v\left(t-t^{\prime \prime}\right)\right]^{-\frac{1}{2}} d t^{\prime \prime} .
$$


In order to calculate higher order terms of eq 3 a Fourier sine transform with respect to $y$ is used. The Fourier sine transform and its inverse transform are respectively

$$
\bar{u}_{i}=\int_{0}^{\infty} u_{i} \sin y s d y \text { and } u_{i}=\frac{2}{\pi} \int_{0}^{\infty} \bar{u}_{i} \sin y s d s .
$$

Multiplying eq 4 by sinys, integrating the second term twice and using the boundary conditions on $u_{i}(x, y, t)$ gives

$$
\frac{\partial \bar{u}_{i}}{\partial t}+v s^{2} \bar{u}_{i}^{2}=\int_{0}^{\infty} f_{i}(x, y, t) \sin y s d y
$$

This is a first order non-homogeneous linear differential equation, with solution

$$
\bar{u}_{i}=\exp \left(-v s^{2} t\right) \int_{0}^{t} \exp \left(v s^{2} t^{\prime}\right) \int_{0}^{\infty} f_{i}\left(x, y, t^{\prime}\right) \sin y s d y d t^{\prime}+C \exp \left(-v s^{2} t\right) .
$$

According to the third boundary condition, when $t=0, u_{i}=0$ and therefore, $\bar{u}_{i}=0$. This gives $C=0$. Using the inverse Fourier sine transform the solution $u_{i}$ is obtained:

$$
u_{i}=\frac{2}{\pi} \int_{0}^{\infty} \int_{0}^{t} \int_{0}^{\infty} \exp \left[-v s^{2}\left(t-t^{\prime}\right)\right] f_{i}\left(x, y^{\prime}, t^{\prime}\right) \sin y s \sin y^{\prime} s d y^{\prime} d t^{\prime} d s .
$$

Integrating with respect to $s$ this equation reduces to

$$
u_{i}=\frac{1}{2(\pi v)^{\frac{1}{2}}} \int_{0}^{t} \int_{0}^{\infty} \frac{f_{i}\left(x, y^{\prime}, t^{\prime}\right)}{\left(t-t^{\prime}\right)^{\frac{1}{2}}}\left\{\exp \left[-\frac{\left(y-y^{\prime}\right)^{2}}{4 v\left(t-t^{\prime}\right)}\right]-\exp \left[-\frac{\left(y+y^{\prime}\right)^{2}}{4 v\left(t-t^{\prime}\right)}\right]\right\} d y^{\prime} d t^{\prime} .
$$

\section{SKIN FRICTION}

The skin friction can also be expressed in series forrn:

$$
\tau=\sum_{i=0}^{n} \mu\left(\frac{\partial u_{i}}{\partial y}\right)_{y=0}
$$

in which $\tau$ is the shear stress and $\mu$ denotes dynamic viscosity. The derivatives of the approximation terms at $y=0$ are

$$
\left(\frac{\partial u_{0}}{\partial y}\right)_{y=0}=\frac{1}{(\pi v)^{\frac{1}{2}}} \int_{0}^{t} \frac{\frac{\partial U}{\partial t^{\prime \prime}}}{\left(t-t^{\prime \prime}\right)^{\frac{1}{2}}} d t^{\prime \prime}
$$


and for $i=1,2,3 \ldots$

$$
\begin{aligned}
\left(\frac{\partial u_{i}}{\partial y}\right)_{y=0}= & \frac{1}{(\pi v)^{\frac{1}{2}}}\left\{\int_{0}^{t} \frac{f_{i}\left(x, 0, t^{\prime}\right)}{\left(t-t^{\prime}\right)^{\frac{1}{2}}} d t^{\prime}\right. \\
& \left.+\int_{0}^{t \infty} \frac{1}{\left(t-t^{\prime}\right)^{\frac{1}{2}}} \frac{\partial f_{i}}{\partial y} \exp \left[-\frac{y^{\prime^{2}}}{4 v\left(t-t^{\prime}\right)}\right]\right\} d t^{\prime} d y^{\prime} .
\end{aligned}
$$

Substituting expressions 23 and 24 for $u_{i}$ in eq 22 ,

$$
\tau=\frac{\mu}{(\pi v)^{\frac{1}{2}}} \int_{0}^{t} \frac{\frac{\partial U}{\partial t}+U \frac{\partial U}{\partial x}}{\left(t-t^{\prime}\right)^{\frac{1}{2}}}+\frac{\mu}{(\pi v)^{\frac{1}{2}}} \int_{0}^{t} \int_{0}^{\infty} \frac{\exp \left[-\frac{y^{\prime^{2}}}{4 v\left(t-t^{\prime}\right)}\right]}{\left(t-t^{\prime}\right)^{\frac{1}{2}}} \sum_{i=1}^{n} \frac{\partial f_{j}}{\partial y^{\prime}} d y^{\prime} d t^{\prime}
$$

is obtained. This is a series solution for the skin friction. The number of approximation terms depends on the type of motion, the shape of the body and the degree of accuracy required by the problem.

\section{APPLICATION}

$\underline{U}=\left(a_{1} t+a_{2} t^{2}+a_{3} t^{3}+a_{4} t^{4}\right) h(x)$

In this example the terms for $i=\sigma, 1$ and 2 of series 7 are calculated. The first integral term is

$$
\begin{aligned}
& \int_{0}^{t} \frac{\frac{\partial U}{\partial t}+U \frac{\partial U}{\partial x}}{\left(t-t^{\prime}\right)^{\frac{1}{2}}} d t^{\prime}=\left\{2 a_{1}+2.667 a_{2} t+1.067\left(3 a_{3}+\frac{d h}{d x} a_{1}^{2}\right) t^{2}\right. \\
& +0.914\left(4 a_{4}+2 \frac{d h}{d x} a_{1} a_{2}\right) t^{3}+0.813\left(2 a_{1} a_{3}+a_{2}^{2}\right) \frac{d h}{d x} t^{4}+1.478\left(a_{2} a_{3}+\right. \\
& \left.+a_{1} a_{4}\right) \frac{d h}{d x} t^{5}+0.682\left(2 a_{2} a_{4}+a_{3}^{2}\right) \frac{d h}{d x} t^{6}+1.273 a_{2} a_{4} \frac{d h}{d x} t^{7}+ \\
& \left.+0.599 a_{4}^{2} \frac{d h}{d x} t^{8}\right\} h t^{\frac{1}{2}} .
\end{aligned}
$$

The zeroth order approximation term for velocity is

$$
u_{0}=h \int_{0}^{t} \operatorname{erf} \frac{y}{2\left[v\left(t-t^{\prime \prime}\right)\right]^{\frac{1}{2}}}\left(a_{1}+2 a_{2} t^{\prime \prime}+3 a_{3} t^{\prime \prime 2}+4 a_{4} t^{\prime \prime 3}\right) d t^{\prime \prime}
$$


The integration leads to

$$
u_{0}=h\left\{2 t a_{1} F_{0}(\eta)+4 a_{2} t^{2} F_{1}(\eta)+6 a_{3} t^{3} F_{2}(\eta)+8 a_{4} t^{4} F_{3}(\eta)\right\}
$$

where $F_{0}, F_{1}, F_{2}$ and $F_{3}$ are functions of $\eta=\frac{y}{2(\nu t)^{\frac{1}{2}}}$.

$$
\begin{aligned}
F_{0}= & \operatorname{erf} \eta\left(\eta^{2}+\frac{1}{2}\right)+\pi^{-\frac{1}{2}} \eta e^{-\eta^{2}}-\eta^{2} \\
F_{1}= & \operatorname{erf} \eta\left(\frac{\eta^{4}}{3}+\eta^{2}+\frac{1}{4}\right)+\pi^{-\frac{1}{2}} e^{-\eta^{2}\left(\frac{5}{6} \eta+\frac{1}{3} \eta^{3}\right)-\eta^{2}-\frac{1}{3} \eta^{4}} \\
F_{2}= & \operatorname{erf} \eta\left(\frac{1}{6}+\eta^{2}+\frac{2}{3} \eta^{4}+-\frac{4}{45} \eta^{6}\right)+\pi^{-\frac{1}{2}} e^{-\eta^{2}}\left(\frac{11}{15} \eta+\frac{28}{45} r^{3}+\right. \\
& \left.\frac{4}{45} \eta^{5}\right)-\eta^{2}-\frac{2}{3} \eta^{4}-\frac{4}{45} \eta^{6} \\
F_{3}= & \operatorname{erf} \eta\left(\frac{1}{8}+\eta^{2}+\eta^{4}+\frac{4}{15} \eta^{6}+\frac{2}{105} \eta^{8}\right)+\pi^{-\frac{1}{2}} e^{-\eta^{2}}\left(\frac{93}{140} \eta+\right. \\
& \left.\frac{37}{42} \eta^{3}+\frac{9}{35} \eta^{5}+\frac{2}{105} \eta^{7}\right)-\eta^{2}-\eta^{4}-\frac{4}{15} \eta^{6}-\frac{2}{105} \eta^{8} .
\end{aligned}
$$

The next step is the calculation of $\frac{\partial f_{1}}{\partial y^{1}}$. To do this expressions for $\frac{\partial^{2} u_{0}}{\partial y \partial x}$, $v_{0}$ and $\frac{\partial^{2} u_{0}}{\partial y^{2}}$ are needed.

It can be shown that

$$
\frac{\partial^{2} u_{0}}{\partial y \partial x}=(v t)^{-\frac{1}{2}} \frac{d h}{d x}\left\{a_{1} G_{0}^{\prime} t+2 a_{2} G_{1} t^{2}+3 a_{3} G_{2} t^{3}+4 a_{4} G_{3} t^{4}\right\}
$$

in which $G_{0}, G_{1}, G_{2}$ and $G_{3}$ are some functions of $\eta$.

$$
\begin{aligned}
\mathrm{G}_{0}= & 2 \eta \operatorname{erf} \eta+2 \pi^{-\frac{1}{2}} \mathrm{e}^{-\eta^{2}}-2 \eta \\
\mathrm{G}_{1}= & \operatorname{erf} \eta\left(\frac{4}{3} \eta^{3}+2 \eta\right)+\pi^{-\frac{1}{2}} \mathrm{e}^{-\eta^{2}}\left(\frac{4}{3}+\frac{4}{3} \eta^{2}\right)-\frac{4}{3} \eta^{3}-2 \eta \\
\mathrm{G}_{2}= & \operatorname{erf} \eta\left(\frac{8}{15} \eta^{5}+\frac{8}{3} \eta^{3}+2 \eta\right)+\pi^{-\frac{1}{2}} \mathrm{e}^{-\eta^{2}}\left(\frac{16}{15}+\frac{12}{5} \eta^{2}+\frac{8}{15} \eta^{4}\right)- \\
& 2 \eta-\frac{8}{3} \eta^{3}-\frac{8}{15} \eta^{5} \\
\mathrm{G}_{3}= & \operatorname{erf} \eta\left(\frac{16}{105} \eta^{7}+\frac{24}{15} \eta^{5}+4 \eta^{3}+2 \eta\right)+\pi^{-\frac{1}{2}} e^{-\eta^{2}}\left(\frac{32}{35}+\frac{116}{35} \eta^{2}+\right. \\
& \left.+\frac{32}{21} \eta^{4}+\frac{16}{105} \eta^{6}\right)-2 \eta-4 \eta^{3}-\frac{72}{45} \eta^{5}-\frac{16}{105} \eta^{7}
\end{aligned}
$$

and 


$$
\begin{aligned}
\frac{\partial^{2} u_{0}}{\partial y^{2}}= & \frac{h}{2 \nu}\left\{a_{1} s_{0}+2 a_{2}\left(s_{0}-s_{1}\right) t+3 a_{3}\left(s_{0}-2 s_{1}+s_{2}\right) t^{2}+\right. \\
& \left.4 a_{4}\left(s_{0}-3 s_{1}+3 s_{2}-s_{3}\right)\right\} .
\end{aligned}
$$

In which $s_{0}, s_{1}, s_{2}$ and $s_{3}$ are some functions of $\eta$.

$$
\begin{aligned}
& s_{0}=-2 \operatorname{erfc} \eta \\
& s_{1}=4 \eta^{2} \operatorname{erfc} \eta-4 \pi^{-\frac{1}{2}} \eta e^{-\eta^{2}} \\
& s_{2}=-\frac{8}{3} \eta^{4} \operatorname{erfc} \eta+\frac{4}{3} \pi^{-\frac{1}{2}}\left(2 \eta^{3}-\eta\right) e^{-\eta^{2}} \\
& s_{3}=\frac{16}{15} \eta^{6} \operatorname{erfc} \eta-\frac{4}{5} \pi^{-\frac{1}{2}}\left(\frac{4}{3} \eta^{5}-\frac{2}{3} \eta^{3}+\eta\right) e^{-\eta^{2}} .
\end{aligned}
$$

Using the continuity equation (eq 5) $v_{0}$ can be calculated.

$$
\begin{aligned}
v_{0}= & -4(v t)^{\frac{1}{2}} \frac{d h}{d x}\left\{a_{1} v_{0} t+2 a_{2}\left(V_{0}-v_{1}\right) t^{2}+3 a_{3}\left(v_{0}-2 v_{1}+v_{2}\right) t^{3}\right. \\
& \left.+4 a_{4}\left(V_{0}-3 v_{1}+3 v_{2}-v_{3}\right) t^{4}\right\}
\end{aligned}
$$

in which $V_{0}, V_{1}, V_{2}$ and $V_{3}$ are some functions of $\eta$.

$$
\begin{aligned}
\mathrm{V}_{0}= & \operatorname{erf} \eta\left(\frac{1}{2} \eta+\frac{1}{3} \eta^{3}\right)+\pi^{-\frac{1}{2}}\left(\frac{1}{3}+\frac{1}{3} \eta^{2}\right) e^{-\eta^{2}}-\frac{1}{3} \eta^{3}-\frac{1}{3} \pi^{-\frac{1}{2}} \\
\mathrm{~V}_{1}= & \operatorname{erf} \eta\left(\frac{1}{4} \eta-\frac{1}{15} \eta^{5}\right)+\pi^{-\frac{1}{2}}\left(\frac{1}{5}+\frac{1}{30} \eta^{2}-\frac{1}{15} \eta^{4}\right) e^{-\eta^{2}} \\
& +\frac{1}{15} \eta^{5}-\frac{1}{5} \pi^{-\frac{1}{2}} \\
\mathrm{~V}_{2}= & \operatorname{erf} \eta\left(\frac{1}{6} \eta+\frac{4}{315} \eta^{7}\right)+\pi^{-\frac{1}{2}}\left(\frac{1}{7}+\frac{1}{105} \eta^{2}-\frac{2}{315} \eta^{4}+\frac{4}{315} \eta^{6}\right) e^{-\eta^{2}} \\
& -\frac{4}{315} \eta^{7}-\frac{1}{7} \pi^{-\frac{1}{2}} \\
\mathrm{~V}_{3}= & \operatorname{erf} \eta\left(\frac{1}{8} \eta-\frac{2}{945} \eta^{9}\right)+\pi^{-\frac{1}{2}}\left(\frac{1}{9}+\frac{1}{252} \eta^{2}-\frac{1}{630} \eta^{4}+\frac{1}{945} \eta^{6}\right. \\
& \left.-\frac{2}{945} \eta^{8}\right) e^{-\eta^{2}}+\frac{2}{945} \eta^{9}-\frac{1}{9} \pi^{-\frac{1}{2}} .
\end{aligned}
$$

Now $\frac{\partial f_{1}}{\partial y^{\prime}}$ can be calculated:

$$
\begin{aligned}
& -\frac{\partial f_{1}}{\partial y}=\left\{2 t a_{1}^{2} \lambda_{1}+4 t^{2} a_{1} a_{2} \lambda_{2}+6 t^{3} a_{1} a_{3} \lambda_{3}+8 t^{3} a_{2}{ }^{2} \lambda_{4}+8 t^{4} a_{1} a_{4} \lambda_{5}+\right. \\
& \left.+12 t^{4} a_{2} a_{3} \lambda_{6}+16 t^{5} a_{2} a_{4} \lambda_{7}+18 t^{5} a_{3}{ }^{2} \lambda_{8}+24 t^{6} a_{3} a_{4} \lambda_{9}+32 t^{7} a_{4}{ }^{2} \lambda_{1}\right\} h \frac{d h}{d x}\left(\frac{t}{v}\right)^{\frac{1}{2}}
\end{aligned}
$$


in which $\lambda_{i}, i=1$ to 10 , are some functions of $\eta$ which involve $F_{j}, s_{j}, G_{j}$ and $V_{j}$, $j=0$ to 3 .

The next step is to multiply $\frac{\partial f_{1}}{\partial y^{\prime}}$ with $\exp \left[-\frac{y^{\prime 2}}{4 v\left(t-t^{\prime}\right)}\right]\left(t-t^{\prime}\right)^{-\frac{1}{2}}$ and to inte-

grate with respect to $t^{\prime}$. Substituting $t /\left(t-t^{\prime}\right)=a$ and carrying out the integration the following result is obtained.

$$
\begin{aligned}
& \int_{0}^{t} \int_{0}^{\infty} \frac{\exp \left[-\frac{y^{\prime^{2}}}{4 \nu\left(t-t^{\prime}\right)}\right]}{\left(t-t^{\prime}\right)^{\frac{1}{2}}} \frac{\partial f_{1}}{\partial y^{\prime}} d y^{\prime} d t^{\prime}=-\left\{4 t^{2} a_{1}{ }^{2} I_{1}+8 t^{3} a_{1} a_{2} I_{2}+\right. \\
& +12 t^{4} a_{1} a_{3} I_{3}+16 t^{4} a_{2}{ }^{2} I_{4}+16 t^{5} a_{1} a_{4} I_{5}+24 t^{5} a_{2} a_{3} I_{6}+32 t^{6} a_{2} a_{4} I_{7}+ \\
& \left.+36 t^{6} a_{3}{ }^{2} I_{8}+48 t^{7} a_{3} a_{4} I_{9}+64 t^{8} a_{4}^{2} I_{10}\right\} h \frac{d h}{d x} t^{\frac{1}{2}}
\end{aligned}
$$

where

$$
I_{i}=\int_{0}^{\infty} \lambda_{i} \phi d \eta \quad \text { for } i=1,2, \ldots 10
$$

where $\mathrm{i}$ refers to the terms of the series in eq $37 \mathrm{a}$ and $\phi$ is a function of $\eta$ calculated from the integral

$$
\phi(j, \eta)=e^{2} \int_{1}^{\infty} e^{-\eta^{2} a} \frac{(a-1)^{\frac{j+1}{2}}}{a \frac{j+4}{2}} d a
$$

where $j$ is the numerator of the power of $t$ in eq 36 , every term of which can be expressed in the form of $a_{m} a_{n} \lambda_{i} t^{j / 2}$. The functions $\phi(j, \eta)$ are tabulated in Appendix A.

The integrals $I_{i}$ asymptotically approach constant values as $\eta \rightarrow \infty$. It can be shown that if they are integrated from zero to properly chosen values of $\eta *$, the values of the integrals remain practically unchanged. For example

$$
\begin{array}{ll}
I_{1}=0.0536 \text { for } \eta * \rightarrow \infty & I_{1}=0.0534 \text { for } \eta_{1} *=1.44 \\
I_{2}=0.0429 \text { for } \eta^{*} \rightarrow \infty & I_{2}=0.0428 \text { for } \eta_{1} *=1.44 \\
I_{4}=0.00952 \text { for } \eta * \rightarrow \infty & I_{4}=0.00951 \text { for } \eta_{2} *=1.23 .
\end{array}
$$

The values of $\eta_{1} *$ and $\eta_{2} *$ refer to the boundary layer thicknesses for the cases where $U_{1}=h a_{1} t$ and $U_{2}=h a_{2} t^{2}$ respectively. They are calculated from the relationships $u_{01} / U_{1}=0.99$ and $u_{02} / U_{2}=0.99$ and used as upper limits for the first and fourth integrals since $\lambda_{1} \phi_{1}$ and $\lambda_{4} \phi_{4}$ involve only the functions due to the terms linear and quadratic in t respectively. The second integral involves the cross product terms and therefore the higher value of $\eta^{*}$ is chosen. 
The values of the other integrals are

$$
\begin{aligned}
I_{3} & =0.0237 \text { for } \eta_{1} *=1.44 \\
I_{5} & =0.0151 \text { for } \eta_{1} *=1.44 \\
I_{6} & =0.0112 \text { for } \eta_{2} *=1.23 \\
I_{7} & =0.00751 \text { for } \eta_{2} *=1.23 \\
I_{8} & =0.00345 \text { for } \eta_{3} *=1.09 \\
I_{9} & =0.00477 \text { for } \eta_{3} *=1.09 \\
I_{10} & =0.00168 \text { for } \eta_{4}=0.99 .
\end{aligned}
$$

Now the next term of eq 25 will be calculated. The first order approximation term for velocity should be calculated by using eq 21 . It can be shown that

$$
\begin{aligned}
& f_{1}=h \frac{d h}{d x}\left\{a_{1}^{2} S_{1}(\eta) t^{2}+2 a_{1} a_{2} S_{2}(\eta) t^{3}+2 a_{1} a_{3} S_{3}(\eta) t^{4}\right. \\
& +a_{2}^{2} S_{4}(\eta) t^{4}+2 a_{1} a_{4} S_{5}(\eta) t^{5}+2 a_{2} a_{3} S_{6}(\eta) t^{5}+2 a_{2} a_{4} S_{7}(\eta) t^{6} \\
& \left.+a_{3}{ }^{2} S_{8}(\eta) t^{6}+2 a_{3} a_{4} S_{9}(\eta) t^{7}+a_{4}^{2} S_{10}(\eta) t^{8}\right\}
\end{aligned}
$$

where $S_{i}(\eta), i=1$ to 10 , are some functions of $\eta$ calculated from eq $6 \mathrm{~b}$. The terms of $f_{1}$ are to be multiplied with the kernel in eq 21 and integrated. Since the $S_{i}(\eta)$ functions are quite involved, they are approximated to fifth degree polynomials in $\eta$ by using the least squares method.

The next step is the integration in accordance with eq 21 . Each term has the form of

$$
u_{1 i}=\frac{1}{2}(\pi \nu)^{-\frac{1}{2}} h \cdot \frac{d h}{d x} \int_{0}^{t} \int_{0}^{\infty} \frac{t^{\prime m_{i}} \sum_{0}^{5} A_{i n} \eta^{n}}{\left(t-t^{\prime}\right)^{\frac{1}{2}}}\{K\} d y^{\prime} d t^{\prime}
$$

in which $\mathrm{K}$ denotes the kernel. Changing the variables $\mathrm{t}^{\prime}=\mathrm{a}^{2} \mathrm{t}$ and observing that $y^{\prime}=2\left(v t^{\prime}\right)^{\frac{1}{2}} \eta^{\prime}$ and $y=2(v t)^{\frac{1}{2}} \eta$, $u_{l i}$ can be written in the following form

$$
u_{i i}=2 \pi^{-\frac{1}{2}} h \frac{d h}{d x} t^{m_{i+1}} \sum_{0}^{n} A_{i n} \int_{0}^{1} \int_{0}^{\infty} \frac{a^{2\left(m_{i}+1\right)}\{K\} \eta^{\prime n}}{\left(1-a^{2}\right)^{\frac{1}{2}}} d \eta^{\prime} d a .
$$

Since the value of $u_{1 i}$ becomes small at the edge of the boundary layer, the upper limit of the integral is changed from $\infty$ to $\eta_{i}^{*}$ and the integration with respect to $\eta^{\prime}$ is performed for each term of the polynomial, i.e., for the values of $n$ varying from 0 to 5 . The results are shown in Appendix B. Next, the integration with respect to $a$ is carried out by a digital computer at chosen values of $\eta$ with the values of $m_{i}$ varying from 2 to 8 . Thus, eq 42 reduces to 


$$
u_{1 i}=2 \pi^{-\frac{1}{2}} h \frac{d h}{d x} t^{m_{i}+1} \sum_{0}^{5} A_{i n} C_{n i}(\eta)
$$

where the values of $C_{n i}$ are tabulated in Appendix $C$. The values of $u_{\perp i}$ are calculated at chosen values of $\eta$ and the results a re approximated to tenth degree polynomials in $\eta$ by using the least squares method. Thus, an approximate expression for $\mathrm{u}_{1}$ is obtained.

$$
\begin{aligned}
& u_{1}=h \frac{d h}{d x} \frac{2}{\sqrt{\pi}}\left\{a_{1}^{2} g_{1}(\eta) t^{3}+2 a_{1} a_{2} g_{2}(\eta) t^{4}+2 a_{1} a_{3} g_{3}(\eta) t^{5}\right. \\
& +a_{2}^{2} g_{4}(\eta) t^{5}+2 a_{1} a_{4} g_{5}(\eta) t^{6}+2 a_{2} a_{3} g_{6}(\eta) t^{6}+2 a_{2} a_{4} g_{7}(\eta) t^{7}+a_{3}^{2} g_{8}(\eta) t^{7} \\
& \left.+2 a_{3} a_{4} g_{9}(\eta) t^{8}+a_{4}^{2} g_{10}(\eta) t^{9}\right\}
\end{aligned}
$$

where $g_{i}(\eta), i=1$ to 10 , are tenth degree polynomials in $\eta$. Since in this calculation process two approximations with the least squares method are involved, it is advisable to check the accuracy of the expression for $u_{1}$. To do this, ' $u_{1}$ is inserted in eq 4 and it is found that for all practical purposes the equality is verified. In this connection it should also be pointed out that the values of $g_{1}(\eta)$ should be the same as the values of Blasius' $\zeta_{3}{ }^{\prime}$ function multiplied by $\frac{1}{2} \pi^{\frac{1}{2}}$. In order to make the comparison both of these functions are plotted in Figure 1. The values of the functions up to $\eta=0.8$ are practically the same and the curves deviate slightly from each other above $\eta=0.8$. This is further evidence that the polynomial approximations are satisfactory. Incidentally the value of Blasius' function at $\eta=1.0$ is 0.069 and not 0.02 as tabulated by Blasius.

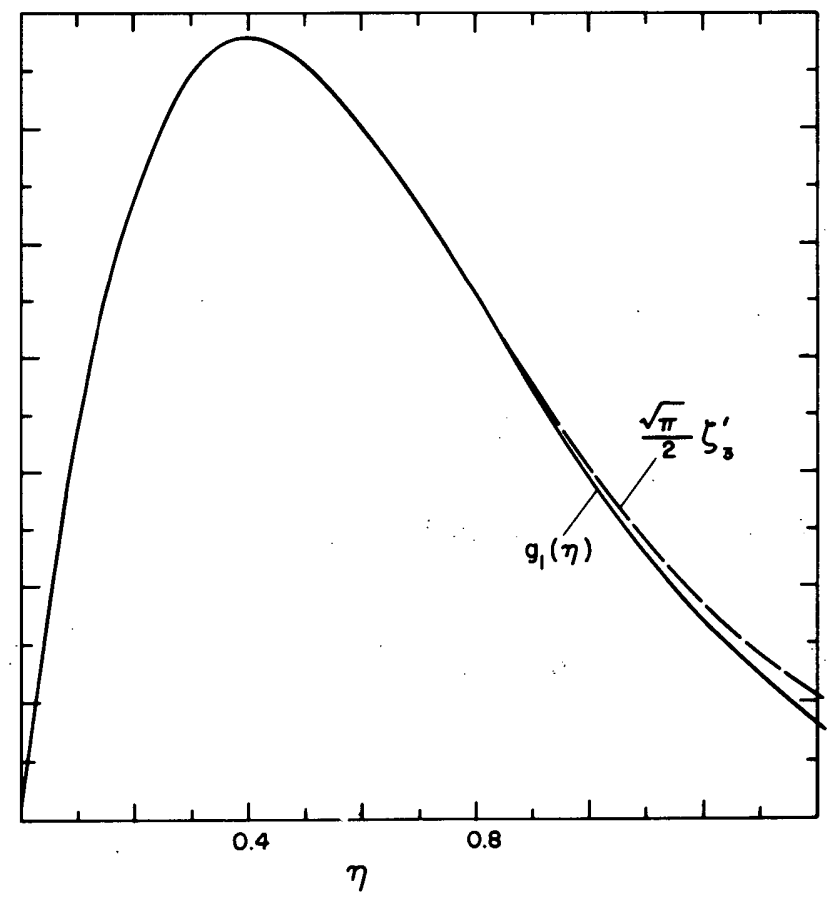

Figure 1. Comparison of $g_{1}(\eta)$ with Blasius' $\frac{1}{2} \pi^{\frac{1}{2}} \zeta_{3}^{\prime}$ function. 
Now $\frac{\partial f_{2}}{\partial y}$ can be calculated.

$$
\begin{aligned}
& \frac{\partial f_{2}}{\partial y}=-h(\pi \nu)^{-\frac{1}{2}} \frac{d}{d x}\left(n \frac{d h}{d x}\right)\left\{2 a_{1}{ }^{3} t^{7 / 2}\left[F_{0} \frac{d g_{1}}{d \eta}+s_{0} e_{1}\right]+4 a_{1}{ }^{2} a_{2} t^{9 / 2}\right. \\
& {\left[\left(F_{0} \frac{d g_{2}}{d \eta}+s_{0} e_{2}\right)+\left(F_{1} \frac{d g_{1}}{d \eta}+s_{1 t} e_{1}\right)\right]+4 a_{1}^{2} a_{3} t^{11 / 2}\left[\left(F_{0} \frac{d g_{3}}{d \eta}+s_{0} e_{3}\right)+1.5\right.} \\
& \left.\left(F_{2} \frac{d g_{1}}{d \eta}+s_{2 t} e_{1}\right)\right]+2 a_{1} a_{2}^{2} t^{11 / 2}\left[\left(F_{0} \frac{d g_{4}}{d \eta}+s_{0} e_{4}\right)+4\left(F_{1} \frac{d g_{2}}{d \eta}+s_{1 t} e_{2}\right)\right] \\
& +4 a_{1}^{2} a_{4} t^{13 / 2}\left\{\left(F_{0} \frac{d g_{5}}{d \eta}+s_{0} e_{5}\right)+2\left(F_{3} \frac{d g_{1}}{d \eta}+s_{3} e_{1}\right)\right]+4 a_{1} a_{2} a_{3} t^{13 / 2} \\
& {\left[\left(F_{0} \frac{d g_{6}}{d \eta}+s_{0} e_{6}\right)+2\left(F_{1} \frac{d g_{3}}{d \eta}+s_{1 t} e_{3}\right)+3\left(F_{2} \frac{d g_{2}}{d \eta}+s_{2 t} e_{2}\right)\right]+4 a_{2}{ }^{3} t^{13 / 2}} \\
& \left.\mid F_{1} \frac{d g_{4}}{d \eta}+s_{1 t} e_{4}\right]+4 a_{1} a_{2} a_{4} t^{15 / 2}\left[\left(F_{0} \frac{d g_{7}}{d \eta}+s_{0} e_{7}\right)+2\left(F_{1} \frac{d g_{5}}{d \eta}+s_{1} t e_{5}\right)\right. \\
& \left.+4\left(F_{3} \frac{d g_{2}}{d \eta}+s_{3} t e_{2}\right)\right]+2 a_{1} a_{3}^{2} t^{15 / 2}\left[\left(F_{0} \frac{d g_{8}}{d \eta}+s_{0} e_{8}\right)+6\left(F_{2} \frac{d g_{3}}{d \eta}+s_{2} t e_{3}\right)\right] \\
& +8 a_{2}{ }^{2} a_{3} t^{15 / 2}\left[\left(F_{1} \frac{d g_{6}}{d \eta}+s_{1} e_{6}\right)+0.75\left(F_{2} \frac{d g_{4}}{d \eta}+s_{2} t e_{4}\right)\right]+4 a_{1} a_{3} a_{4} t^{17 / 2} \\
& {\left[\left(F_{0} \frac{d g_{9}}{d \eta}+s_{0} e_{9}\right)+3\left(F_{2} \frac{d g_{5}}{d \eta}+s_{2} e_{5}\right)+4\left(F_{3} \frac{d g_{3}}{d \eta}+s_{3} e_{3}\right)\right]+8 a_{2}{ }^{2} a_{4} t^{17 / 2}} \\
& {\left[\left(F_{1} \frac{d g_{7}}{d \eta}+s_{1 t} e_{7}\right)+\left(F_{3} \frac{d g_{4}}{d \eta}+s_{3 t} e_{4}\right)\right]+4 a_{2} a_{3}^{2} t^{17 / 2}\left[\left(F_{1} \frac{d g_{8}}{d \eta}+s_{1 t} e_{8}\right)\right.} \\
& \left.+3\left(F_{2} \frac{d g_{6}}{d \eta}+s_{2 t} e_{6}\right)\right]+8 a_{2} a_{3} a_{4} t^{19 / 2} \mid\left(F_{1} \frac{d g_{9}}{d \eta}+s_{1 t} e_{9}\right)+1.5\left(F_{2} \frac{d g_{7}}{d \eta}+s_{2 t} e_{7}\right) \\
& \left.+2\left(F_{3} \frac{d g_{6}}{d \eta}+s_{3} e_{6}\right)\right]+6 a_{3}{ }^{3} t^{19 / 2}\left[F_{2} \frac{d g_{8}}{d \eta}+s_{2} t_{3}\right]+2 a_{1} a_{4}{ }^{2} t^{19 / 2} \\
& {\left[\left(F_{0} \frac{d g_{10}}{d \eta}+s_{0} e_{10}\right)+8\left(F_{3} \frac{d g_{5}}{d \eta}+s_{3 t} e_{5}\right)\right]+4 a_{2} a_{4}^{2} t^{21 / 2}\left[\left(F_{1} \frac{d g_{10}}{d \eta}+s_{1 t} e_{10}\right)\right.} \\
& +4\left(F_{3} \frac{d g}{d \eta}+s_{3} e_{7}\right) \mid+12 a_{3}{ }^{2} a_{4} t^{21 / 2}\left[\left(F_{2} \frac{d g_{9}}{d \eta}+s_{2 t} e_{9}\right)+\frac{2}{3}\left(F_{3} \frac{d g_{8}}{d \eta}+s_{3 t} e_{8}\right)\right] \\
& +6 a_{3} a_{4}{ }^{2} t^{23 / 2}\left[\left(F_{2} \frac{d g_{10}}{d \eta}+s_{2} t e_{10}\right)+\frac{8}{3}\left(F_{3} \frac{d g_{9}}{d \eta}+s_{3} t e_{9}\right)\right]+8 a_{4}{ }^{3} t^{25 / 2} \\
& {\left[\left(F_{3} \frac{d g_{10}}{d \eta}+s_{3 t} e_{10} \mid\right\}-(\pi v)^{-\frac{1}{2}} h\left(\frac{d h}{d x}\right)^{2}\left\{2 a_{1}{ }^{3} t^{7 / 2} \mid G_{0} g_{1}-v_{0} \frac{d^{2} g_{1}}{d \eta^{2}}\right\}\right.}
\end{aligned}
$$


$+4 a_{1}^{2} a_{2} t^{9 / 2}\left[\left(G_{0} g_{2}-V_{0} \frac{d^{2} g_{2}}{d \eta^{2}}\right)+\left(G_{1} g_{1}-V_{1 t} \frac{d^{2} g_{1}}{d \eta^{2}}\right)\right]+4 a_{1}{ }^{2} a_{3} t^{11 / 2}$

$\left\lceil\left(G_{0} g_{3}-v_{0} \frac{d^{2} g_{3}}{d \eta^{2}}\right)+1.5\left(G_{2} g_{1}-v_{2 t} \frac{d^{2} g_{1}}{d \eta^{2}}\right)\right]+2 a_{1} a_{2}{ }^{2} t^{11 / 2}\left[\left(G_{0} g_{4}-v_{0} \frac{d^{2} g_{4}}{d \eta^{2}}\right)\right.$

$\left.+4\left(G_{1} g_{2}-V_{1 t} \frac{d^{2} g_{2}}{d \eta^{2}}\right)\right]+4 a_{1}^{2} a_{4} t^{13 / 2}\left[\left(G_{0} g_{5}-v_{0} \frac{d^{2} g_{5}}{d r_{1}^{2}}\right)+2\left(G_{3} g_{1}-V_{3 t} \frac{d^{2} g_{1}}{d \eta^{2}}\right)\right]$

$+4 a_{1} a_{2} a_{3} t^{13 / 2}\left[\left(G_{0} g_{6}-V_{0} \frac{d^{2} g_{6}}{d \eta^{2}}\right)+2\left(G_{1} g_{3}-V_{1} \frac{d^{2} g_{3}}{d \eta^{2}}\right)+3\left(G_{2} g_{2}-V_{2 t} \frac{d^{2} g_{2}}{d \eta^{2}}\right)\right]$

$+4 a_{1} a_{2} a_{4} t^{15 / 2}\left[\left(G_{0} g_{7}-v_{0} \frac{d^{2} g_{7}}{d \eta^{2}}\right)+2\left(G_{1} g_{5}-V_{1 t} \frac{d^{2} g_{5}}{d \eta^{2}}\right)+4\left(G_{3} g_{2}-V_{3 t} \frac{d^{2} g_{2}}{d \eta^{2}}\right)\right]$

$+2 a_{1} a_{3}^{2} t^{15 / 2}\left[\left(G_{0} g_{8}-V_{0} \frac{d^{2} g_{8}}{d \eta^{2}}\right)+6\left(G_{2} g_{3}-v_{2} t \frac{d^{2} g_{3}}{d \eta^{2}}\right)\right]+4 a_{1} a_{3} a_{4} t^{17 / 2}$

$\left[\left(G_{0} g_{9}-V_{0} \frac{d^{2} g_{9}}{d \eta^{2}}\right)+3\left(G_{2} g_{5}-V_{2 t} \frac{d^{2} g_{5}}{d \eta^{2}}\right)+4\left(G_{3} g_{3}-V_{3 t} \frac{d^{2} g_{3}}{d \eta^{2}}\right)\right]+2 a_{1} a_{4}{ }^{2} t^{19 / 2}$

$\left[\left(G_{0} g_{10}-V_{0} \frac{d^{2} g_{10}}{d \eta^{2}}\right)+8\left(G_{3} g_{5}-v_{3 t} \frac{d^{2} g_{5}}{d \eta^{2}}\right)\right]+4 a_{2}{ }^{3} t^{13 / 2}\left[G_{1} g_{4}-v_{1 t} \frac{d^{2} g_{4}}{d \eta^{2}}\right]$

$+8 a_{2}^{2} a_{3} t^{15 / 2}\left[\left(G_{1} g_{6}-v_{1 t} \frac{d^{2} g_{6}}{d \eta^{2}}\right)+0.75\left(G_{2} g_{4}-v_{2 t} \frac{d^{2} g_{4}}{d \eta^{2}}\right)\right]+8 a_{2}^{2} a_{4} t^{17 / 2}$

$\left[\left(G_{1} g_{7}-v_{1 t} \frac{d^{2} g_{7}}{d \eta^{2}}\right)+\left(G_{3} g_{4}-v_{3} \frac{d^{2} g_{4}}{d \eta^{2}}\right)\right]+4 a_{2} a_{3}{ }^{2} t^{17 / 2}\left[\left(G_{1} g_{8}-v_{1 t} \frac{d^{2} g_{8}}{d \eta^{2}}\right)\right.$

$\left.+3\left(G_{2} g_{6}-v_{2 t} \frac{d^{2} g_{6}}{d \eta^{2}}\right)\right]+8 a_{2} a_{3} a_{4} t^{19 / 2}\left[\left(G_{1} g_{9}-v_{1 t} \frac{d^{2} g_{9}}{d \eta^{2}}\right)+1.5\left(G_{2} g_{7}-v_{2 t} \frac{d^{2} g_{7}}{d \eta^{2}}\right)\right.$

$\left.+2\left(G_{3} g_{6}-v_{3 t} \frac{d^{2} g_{6}}{d \eta^{2}}\right)\right]+4 a_{2} a_{4}^{2} t^{21 / 2}\left[\left(G_{1} g_{10}-v_{1 t} \frac{d^{2} g_{10}}{d \eta^{2}}\right)+4\left(G_{3} g_{7}-v_{3 t} \frac{d^{2} g_{7}}{d \eta^{2}}\right)\right]$

$+6 a_{3}{ }^{3} t^{19 / 2}\left[G_{2} g_{8}-V_{2} t \frac{d^{2} g_{8}}{d \eta^{2}}\right]+12 a_{3}{ }^{2} a_{4} t^{21 / 2}\left[\left(G_{2} g_{9}-V_{2 t} \frac{d^{2} g_{9}}{d \eta^{2}}\right)+\frac{2}{3}\right.$

$\left.\left(G_{3} g_{8}-v_{3 t} \frac{d^{2} g_{9}}{d \eta^{2}}\right)\right]+6 a_{3} a_{4}^{2} t^{23 / 2}\left[\left(G_{2} g_{10}-v_{2 t} \frac{d^{2} g_{10}}{d \eta^{2}}\right)+\frac{8}{3}\left(G_{3} g_{9}-v_{3 t} \frac{d^{2} g_{9}}{d \eta^{2}}\right)\right]$

$\left.+8 a_{4}{ }^{3} t^{25 / 2}\left[G_{3} g_{10}-V_{3 t} \frac{d^{2} g_{10}}{d \eta^{2}}\right]\right\}$

where $e_{i}=-\int_{0}^{\eta} g_{i} d \eta, s_{1 t}=s_{0}-s_{1}, s_{2 t}=s_{0}-2 s_{1}+s_{2}, s_{3 t}=s_{0}-3 s_{1}+3 s_{2}-s_{3}$, $\mathrm{V}_{1 \mathrm{t}}=\mathrm{V}_{0}-\mathrm{V}_{1}, \quad \mathrm{~V}_{2 \mathrm{t}}=\mathrm{V}_{0}-2 \mathrm{~V}_{1}+\mathrm{V}_{2}, \mathrm{~V}_{3 \mathrm{t}}=\mathrm{V}_{\mathrm{n}}-3 \mathrm{~V}_{1}+3 \mathrm{~V}_{2}-\mathrm{V}_{3}$.

Each term of this equation has the form of $a_{m} a_{n} a_{k} t^{j / 2} X_{p}(\eta)$ where $X_{p}$ is the function of $\eta$ in the brackets. Each term is to be multiplied with 
$\exp \left[-\frac{y^{\prime^{2}}}{4 v\left(t-t^{\prime}\right)}\right]\left(t-t^{\prime}\right)^{-\frac{1}{2}}$ and integrated with respect to $t^{\prime}$. By substituting $\frac{t}{t-t^{\prime}}=a$ and integrating with respect to $a, \phi(j, \eta)$ functions, where $j$ is the numerator of the power of $t$, are obtained. They are tabulated in Appendix A. Thus, each term can be written in form of $a_{m} a_{n} a_{k} t^{j+2 / 2} \int_{0}^{\infty} \phi(j, \eta) x_{p}(\eta) d \eta$. Changing the upper limit of these integrals from $\infty$ to $\eta_{\mathrm{p}}^{*}$ and performing the integration, the following result is obtained.

$$
\begin{aligned}
& \int_{0}^{t} \int_{0}^{\infty} \frac{\operatorname{expf}\left[-\frac{y^{\prime^{2}}}{4\left(t-t^{\prime}\right)}\right]}{\left(t-t^{\prime}\right)^{\frac{1}{2}}} \frac{\partial f_{2}}{\partial y^{\prime}} d y^{\prime} d t^{\prime}=-2 h t^{\frac{1}{2}}\left\{a _ { 1 } { } ^ { 3 } t ^ { 4 } \left[0.00956 h \frac{d^{2} h}{d x^{2}}\right.\right. \\
& \left.+0.0282\left(\frac{d h}{d x}\right)^{2}\right]+a_{1}^{2} a_{2} t^{5}\left[0.0229 h \frac{d^{2} h}{d x^{2}}+0.0828\left(\frac{d h}{d x}\right)^{2}\right]+a_{1}^{2} a_{3} t^{6}\left[0.0195 h \frac{d^{2} h}{d x^{2}}\right. \\
& \left.+0.0531\left(\frac{d h}{d x}\right)^{2}\right]+a_{1} a_{2}{ }^{2} t^{6}\left[0.0182 h \frac{d^{2} h}{d x^{2}}+0.0508\left(\frac{d h}{d x}\right)^{2}\right]+a_{1}^{2} a_{4} t^{7}\left[0.0172 h \frac{d^{2} h}{d x^{2}}\right. \\
& \left.+0.0455\left(\frac{d h}{d x}\right)^{2}\right]+a_{1} a_{2} a_{3} t^{7}\left[0.0309 h \frac{d^{2} h}{d x^{2}}+0.0856\left(\frac{d h}{d x}\right)^{2}\right]+a_{2}{ }^{3} t^{7} \\
& {\left[0.00485 \mathrm{~h} \frac{\mathrm{d}^{2} \mathrm{~h}}{\mathrm{dx}^{2}}+0.0136\left(\frac{\mathrm{dh}}{\mathrm{dx}}\right)^{2}\right]+\mathrm{a}_{1} \mathrm{a}_{2} \mathrm{a}_{4} \mathrm{t}^{8}\left[0.0266 \mathrm{~h} \frac{\mathrm{d}^{2} \mathrm{~h}}{\mathrm{dx}^{2}}+0.108\left(\frac{\mathrm{dh}}{\mathrm{dx}}\right)^{2}\right]+} \\
& a_{1} a_{3}{ }^{2} t^{8}\left[0.0134 h \frac{d^{2} h}{d x^{2}}+0.0405\left(\frac{d h}{d x}\right)^{2}\right]+a_{2}{ }^{2} a_{3} t^{8}\left[0.0113 h \frac{d^{2} h}{d x^{2}}+0.0649\left(\frac{d h}{d x}\right)^{2}\right]+ \\
& a_{1} a_{3} a_{4} t^{9}\left[0.0258 h \frac{d^{2} h}{d x^{2}}+0.0677\left(\frac{d h}{d x}\right)^{2}\right]+a_{2}{ }^{2} a_{4} t^{9}\left[0.0119 h \frac{d^{2} h}{d x^{2}}+0.032\left(\frac{d h}{d x}\right)^{2}\right]+ \\
& a_{2} a_{3}{ }^{2} t^{9}\left[0.0136 h \frac{d^{2} h}{d x^{2}}+0.0311\left(\frac{d h}{d x}\right)^{2}\right]+a_{2} a_{3} a_{4} t^{10}\left[0.0246 h \frac{d^{2} h}{d x^{2}}+0.0662\left(\frac{d h}{d x}\right)^{2}\right]+ \\
& \mathrm{a}_{3}{ }^{3} \mathrm{t}^{10}\left[0.00357 \mathrm{~h} \frac{\mathrm{d}^{2} \mathrm{~h}}{\mathrm{dx}^{2}}+0.00943\left(\frac{\mathrm{dh}}{\mathrm{dx}}\right)^{2}\right]+\mathrm{a}_{1} \mathrm{a}_{4}{ }^{2} \mathrm{t}^{10}\left[0.014 \mathrm{~h} \frac{\mathrm{d}^{2} \mathrm{~h}}{\mathrm{dx}^{2}}+0.0374\left(\frac{\mathrm{dh}}{\mathrm{dx}}\right)^{2}\right]+ \\
& a_{2} a_{4}^{2} t^{11}\left[0.016 h \frac{d^{2} h}{d^{2}}+0.0432\left(\frac{d h}{d x}\right)^{2}\right]+a_{3}{ }^{2} a_{4} t^{11}\left[0.0121 h \frac{d^{2} h}{d_{x^{2}}}+0.0303\left(\frac{d h}{d x}\right)^{2}\right]+ \\
& \left.\mathrm{a}_{3} \mathrm{a}_{4}{ }^{2} \mathrm{t}^{12}\left[0.0145 \mathrm{~h} \frac{\mathrm{d}^{2} \mathrm{~h}}{\mathrm{dx}^{2}}+0.0342\left(\frac{\mathrm{dh}}{\mathrm{dx}}\right)^{2}\right]+\mathrm{a}_{4}{ }^{3} \mathrm{t}^{13}\left[0.0057 \mathrm{~h} \frac{\mathrm{d}^{2} \mathrm{~h}}{\mathrm{dx}^{2}}+0.0115\left(\frac{\mathrm{dh}}{\mathrm{dx}}\right)^{2}\right]\right\} \text {. }
\end{aligned}
$$

Higher order approximation terms for $\tau$ and $u$ can be calculated in the same manner. Polynomial approximations are quite accurate and can be successfully used to calculate approximation terms. Generally the coefficients of $h \cdot \frac{d^{2} h}{d x^{2}}$ and $\left(\frac{d h}{d x}\right)^{2}$ rapidly approach their final values. For example, the first set of coefficients changes only by $3 \%$ between $\eta=0.8$ and $\eta=1.4$. Therefore, slight discrepancies in $u$ for high values of $\eta$, such as the discrepancy above $\eta=0.8$ in 
the expression for $g_{1}(\eta)$, have very little effect in the final answers. However, if more accuracy is required, different ranges of $\eta$ may be considered and separate approximations for these ranges may be made. Incidentally the coefficients of $h \frac{d^{2} h}{d x^{2}}$ and $\left(\frac{d h}{d x}\right)^{2}$ for uniform acceleration should be the same as those given by Blasius. Blasius' values are slightly different; they are 0.010 and 0.026 respectively. Apparently Blasius has made a slight numerical error because, when these coefficients are calculated according to Blasius' own formula, the same values as those presented in this paper. are obtained.

\section{CONCLUSION}

The integral solutions (eq 16, 21 and 25) are useful in calculating the successive approximation terms for the shear stress in an unsteady laminar boundary layer. These integral solutions are valid for arbitrary accelerations and in this paper the integrations are carried out for the first two successive approximation terms in an example. The example is chosen so that it mav be useful to the readers in approximation of the other velocity variations.

Generally, it is difficult to calculate these integrals without any approximation. However, as shown in this paper, polynomial approximations leading to accurate results, for most practical purposes, can be made. Higher order successive approximation terms can be readily obtained in a similar manner. Since these calculations can be carried out with a high speed digital computer, the method may prove quite useful in calculation of the successive approximation terms in unsteady boundary layer problems where separation does not take place. Higher order successive approximation terms may not be needed for the cases where separation takes place since generally separation occurs a short time after the onset of the motion.

\section{LITERATURE CITED}

Basset, A.B. (1888) A treatise on hydrodynamics. Cambridge, England: Deighton, Bell and Co., vol. 2, ch. 21 .

Blasius, H. (1908) Grenzschichten in Fluessigkeiten mit kleiner Reibung, Z . Math. u. Phys., vol. 56.

Boltze, E. (1908) Grenzschichten an Rotationskoerpern in Fluessigkeiter mit kleiner Reibung, Thesis, Göttingen.

Goertler, H. (1948) Grenzschichtentstehung an Zylindern bei Anfahrt aus der Ruhe, Arch. Math., vol. 1.

Goldstein, S. and Rosenhead, L. (1936) Boundary layer growth, Proceedings, Cambridge Philosophical Society, vol. 32, p. 392.

Schlichting, H. (1960) Boundary layer theory. New York: McGraw Hill Book Co., Inc.

Watson, E.J. (1955) Boundary layer growth, Proceedings of the Royal Society, A231. 


$$
\begin{aligned}
& \phi \text { Functions } \\
& \phi(3, \eta)=Z_{3}-2 Z_{5}+Z_{7} \\
& \phi(5, \eta)=Z_{3}-3 Z_{5}+3 Z_{7}-Z_{9} \\
& \phi(7, \eta)=Z_{3}-4 Z_{5}+6 Z_{7}-4 Z_{9}+Z_{11} \\
& \phi(9, \eta)=Z_{3}-5 Z_{5}+10 Z_{7}-10 Z_{9}+5 Z_{11}-Z_{13} \\
& \phi(11, \eta)=Z_{3}-6 Z_{5}+15 Z_{7}-20 Z_{9}+15 Z_{11}-6 Z_{13}+Z_{15} \\
& \phi(13, \eta)=Z_{3}-7 Z_{5}+21 Z_{7}-35 Z_{9}+35 Z_{11}-21 Z_{13}+7 Z_{15}-Z_{17} \\
& \phi(15, \eta)=Z_{3}-8 Z_{5}+28 Z_{7}-56 Z_{9}+70 Z_{11}-56 Z_{13}+28 Z_{15}-8 Z_{17}+Z_{19} \\
& \phi(17, \eta)=Z_{3}-9 Z_{5}+36 Z_{7}-84 Z_{9}+126 Z_{11}-126 Z_{13}+84 Z_{15}-36 Z_{17}+9 Z_{19}-Z_{21} \\
& \begin{aligned}
\phi(19, \eta)= & Z_{3}-10 Z_{5}+45 Z_{7}-120 Z_{9}+210 Z_{11}-252 Z_{13}+210 Z_{15}-120 Z_{17}+45 Z_{19} \\
& -10 Z_{21}+Z_{23}
\end{aligned} \\
& \phi(21, \eta)=\begin{array}{l}
Z_{3}-11 Z_{5}+55 Z_{7}-165 Z_{9}+330 Z_{11}-462 Z_{13}+462 Z_{15}-330 Z_{1 j}+165 Z_{19} \\
-55 Z_{21}+11 Z_{23}-Z_{25}
\end{array} \\
& \phi(23, \eta)=Z_{3}-12 Z_{5}+66 Z_{7}-220 Z_{9}+495 Z_{11}-792 Z_{13}+924 Z_{15}-792 Z_{17}+495 Z_{19} \\
& -220 Z_{21}+66 Z_{23}-12 Z_{25}+Z_{27} \\
& \phi(25, \eta)=Z_{3}-13 Z_{5}+78 Z_{7}-286 Z_{9}+715 Z_{11}-1287 Z_{13}+1716 Z_{15}-1716 Z_{17} \\
& +1287 Z_{19}-715 Z_{21}+286 Z_{23}-78 Z_{25}+13 Z_{27}-Z_{29}
\end{aligned}
$$


$Z_{25}=0.08695652-0.00828157 \eta^{2}+0.00087174 \eta^{4}-0.00010256 \eta^{6}$

$Z_{27}=0.08-0.00695652 \eta^{2}+0.00066256 \eta^{4}-0.00006974 \eta^{6}$

$Z_{29}=0.07407407-0.00592593 \eta^{2}+0.00051530 \eta^{4}-0.00004908 \eta^{6}$ 
APPENDIX B

19

Calculation of the integral

$$
J_{n}=\int_{0}^{\eta_{i}^{*}} \frac{a^{2\left(m_{i}+1\right)}\{K\} \eta^{\prime^{n}}}{\left(1-a^{2}\right)^{\frac{1}{2}}} d \eta^{\prime}
$$

where

$$
K=\exp \left[-\frac{\left(\eta-a \eta^{\prime}\right)^{2}}{1-a^{2}}\right]-\exp \left[-\frac{\left(\eta+a \eta^{\prime}\right)^{2}}{1-a^{2}}\right]
$$

for $n=0,1,2,3,4$ and 5 .

$$
\begin{aligned}
& J_{0}=-\frac{(\pi)^{\frac{1}{2}}}{2} a^{2 m+1}\left\{\operatorname{erf} \beta_{1}+\operatorname{erf} \beta_{2}-2 \operatorname{erf} \beta_{0}\right\} \\
& J_{1}=a^{2 m}\left\{\frac{(\pi)^{\frac{1}{2}}}{2} \eta\left(\operatorname{erf} \beta_{2}-\operatorname{erf} \beta_{1}\right)+\frac{\left(1-a^{2}\right)^{\frac{1}{2}}}{2}\left(e^{-\beta_{2}^{2}}-e^{-\beta_{1}^{2}}\right)\right\} \\
& J_{2}=-a^{2 m-1}\left\{\frac{(\pi)^{\frac{1}{2}}}{2}\left[\eta^{2}+\frac{1}{2}\left(1-a^{2}\right)\right]\left[\operatorname{erf} \beta_{1}+\operatorname{erf} \beta_{2}-2 \operatorname{erf} \beta_{0}\right]\right. \\
& +\eta\left(1-a^{2}\right)^{\frac{1}{2}}\left(e^{-\beta_{1}^{2}}+e^{-\beta_{2}^{2}}-2 e^{-\beta_{0}^{2}}\right) \\
& +\frac{1}{2}\left(1-a^{2}\right)\left(2 \beta_{0} e^{-\beta_{0}^{2}}-\beta_{1} e^{-\beta_{1}^{2}}-\beta_{2} e^{-\beta_{2}^{2}}\right) \\
& J_{3}=a^{2 m-2}\left\{\frac{(\pi)^{\frac{1}{2}}}{2}\left[\eta^{3}+\frac{3}{2} \eta\left(1-a^{2}\right)\right]\left[\operatorname{erf} \beta_{2}-\operatorname{erf} \beta_{1}\right]\right. \\
& +\left[\frac{3}{2} \eta^{2}+\frac{1}{2}\left(1-a^{2}\right)\right]\left(1-a^{2}\right)^{\frac{1}{2}}\left(e^{-\beta_{2}^{2}}-e^{-\beta_{1}^{2}}\right)-\frac{3}{2} \eta\left(1-a^{2}\right)\left(\beta_{2} e^{-\beta_{2}^{2}}-\beta_{1} e^{-\beta_{1}^{2}}\right) \\
& +\frac{1}{2}\left(1-a^{2}\right)^{3 / 2}\left(\beta_{2}^{2} e^{-\beta_{2}^{2}}-\beta_{1}^{2} e^{-\beta_{1}^{2}}\right) \mid \\
& J_{4}=-a^{2 m-3}\left\{\frac{(\pi)^{\frac{1}{2}}}{2}\left[\eta^{4}+3 \eta^{2}\left(1-a^{2}\right)+\frac{3}{4}\left(1-a^{2}\right)^{2}\right]\left[\operatorname{erf} \beta_{1}+\operatorname{erf} \beta_{2}-2 \operatorname{erf} \beta_{0}\right]\right. \\
& +\left[2 \eta^{3}+2 \eta\left(1-a^{2}\right)\right]\left(1-a^{2}\right)^{\frac{1}{2}}\left(e^{-\beta_{1}^{2}}+e^{-\beta_{2}^{2}}-2 e^{-\beta_{0}^{2}}\right) \\
& +\left[3 \eta^{2}+\frac{3}{4}\left(1-a^{2}\right)\right]\left(1-a^{2}\right)\left(2 \beta_{0} e^{-\beta_{0}^{2}}-\beta_{1} e^{-\beta_{1}^{2}}-\beta_{2} e^{-\beta_{2}^{2}}\right) \\
& -2 \eta\left(1-a^{2}\right)^{3 / 2}\left(2 \beta_{0}^{2} e^{-\beta_{0}^{2}}-\beta_{1}^{2} e^{-\beta_{1}^{2}}-\beta_{2}^{2} e^{-\beta_{2}^{2}}\right) \\
& \left.+\frac{1}{2}\left(1-a^{2}\right)^{2}\left(2 \beta_{0}{ }^{3} e^{-\beta_{0}^{2}}-\beta_{1}^{3} e^{-\beta_{1}^{2}}-\beta_{2}^{3} e^{-\beta_{2}^{2}}\right)\right\}
\end{aligned}
$$


20

APPENDIX B

$$
\begin{aligned}
J_{5}= & a^{2 m-4}\left\{\frac{(\pi)^{\frac{1}{2}}}{2}\left[\eta^{5}+5 \eta^{3}\left(1-a^{2}\right)+\frac{15}{4} \eta\left(1-a^{2}\right)^{2}\right]\left(\operatorname{erf} \beta_{2}-\operatorname{erf} \beta_{1}\right)\right. \\
& +\left[\frac{5}{2} \eta^{4}+5 \eta^{2}\left(1-a^{2}\right)+\left(1-a^{2}\right)^{2}\right]\left(1-a^{2}\right)^{\frac{1}{2}}\left(e^{-\beta_{2}^{2}}-e^{-\beta_{1}^{2}}\right) \\
& -\left[5 \eta^{3}\left(1-a^{2}\right)+\frac{15}{4} \eta\left(1-a^{2}\right)^{2}\right]\left(\beta_{2} e^{-\beta_{2}^{2}}-\beta_{1} e^{-\beta_{1}^{2}}\right) \\
& +\left[5 \eta^{2}\left(1-a^{2}\right)^{3 / 2}+\left(1-a^{2}\right)^{5 / 2}\right]\left(\beta_{2}^{2} e^{-\beta_{2}^{2}}-\beta_{1}^{2} e^{-\beta_{1}^{2}}\right) \\
& -\frac{5}{2} \eta\left(1-a^{2}\right)^{2}\left(\beta_{2}^{3} e^{-\beta_{2}^{2}}-\beta_{1}^{3} e^{-\beta_{1}^{2}}\right) \\
& -\frac{1}{2}\left(1-a^{2}\right)^{5 / 2}\left(\beta_{2}^{4} e^{-\beta_{2}^{2}}-\beta_{1}^{4} e^{-\beta_{1}^{2}}\right)
\end{aligned}
$$

where

$$
\beta_{1}=\frac{\eta-a \eta_{i}^{*}}{\left(1-a^{2}\right)^{\frac{1}{2}}}, \beta_{2}=\frac{\eta+a \eta_{i}^{*}}{\left(1-a^{2}\right)^{\frac{1}{2}}} \text {, and } \quad \beta_{0}=\frac{\eta}{\left(1-a^{2}\right)^{\frac{1}{2}}} \text {. }
$$


APPENDIX C: Values of $C_{n i}$

\begin{tabular}{|c|c|c|c|c|c|c|}
\hline$\eta$ & $\mathrm{C}_{01}$ & $c_{11}$ & $\mathrm{c}_{21}$ & $c_{31}$ & $c_{41}$ & $c_{51}$ \\
\hline 0.1 & 0.08750 & 0.03122 & 0.01325 & 0.01435 & 0.01341 & 0.0139 \\
\hline rj.z & 0.14959 & 0.06204 & 0.03759 & 0.03007 & 0.323is & 0.32527 \\
\hline 0.3 & 0.19199 & 0.39200 & 0.05972 & 0.04841 & 0.04559 & 0.04745 \\
\hline 0.4 & 0.21991 & 0.22553 & 0.03421 & 0.07035 & 0.06702 & 0.07003 \\
\hline 0.5 & 0.23702 & 0.14736 & 0.11097 & 0.09549 & 0.09354 & 0.09561 \\
\hline 3.5 & 0.24539 & 0.17152 & 0.23937 & 5.12587 & 0.12525 & 0.13455 \\
\hline 0.7 & 0.24822 & 0.19232 & 0.163224 & 0.15054 & 0.15501 & 0.17915 \\
\hline $5 . \%$ & 0.24503 & 1.20830 & 0.19590 & 0.19691 & 0.25907 & 0.23215 \\
\hline 0.3 & 0.23679 & 0.21979 & 0.22012 & 0.23251 & 0.25510 & $\therefore 0.2920 \%$ \\
\hline 1.5 & 0.22351 & 0.22391 & 0.23815 & 0.26339 & 0.30182 & 0.35432 \\
\hline 1.2 & 0.20487 & 0.22943 & 0.24554 & 0.28581 & 0.33937 & 0.41087 \\
\hline 1.2 & 0.15017 & 0.20451 & 0.24112 & 0.29139 & 0.35865 & 0.44790 \\
\hline 1.3 & 0.14846 & 0.17555 & 0.21693 & 0.27181 & 0.34558 & 0.44439 \\
\hline 1.4 & $0.10 \% 5$ & 0.13313 & 0.16809 & 0.21506 & 0.25129 & 0.35934 \\
\hline
\end{tabular}

$i=2$

\begin{tabular}{ccccccc}
\hline$\eta$ & $c_{02}$ & $c_{12}$ & $c_{22}$ & $c_{32}$ & $c_{42}$ & $c_{52}$ \\
\hline 0.1 & 0.07394 & 0.02367 & 0.01251 & 0.00911 & 0.00807 & 0.00307 \\
0.2 & 0.12380 & 0.04712 & 0.02535 & 0.01945 & 0.01725 & 0.01727 \\
0.3 & 0.15637 & 0.07011 & $0.042 j 4$ & 0.03213 & 0.02875 & 0.02893 \\
0.4 & 0.17596 & 0.09236 & 0.06034 & 0.04811 & 0.04377 & 0.04414 \\
0.5 & 0.18917 & 0.11351 & 0.08179 & 0.06804 & 0.05348 & 0.05472 \\
1.6 & 0.19539 & 0.13309 & 0.10473 & 0.09215 & 0.03283 & 0.09214 \\
0.7 & 0.19705 & 0.15053 & 0.12882 & 0.12014 & 0.12025 & 0.12759 \\
0.8 & 0.19493 & 0.16505 & 0.15273 & 0.15097 & 0.15750 & 0.17195 \\
0.9 & 0.18928 & 0.17565 & 0.17467 & 0.18263 & 0.19385 & 0.22410 \\
1.0 & 0.17991 & 0.18106 & 0.19222 & 0.21196 & 0.24039 & 0.28050 \\
1.1 & 0.16627 & 0.17961 & 0.20221 & 0.23428 & 0.27758 & 0.33500 \\
1.2 & 0.14742 & 0.16921 & 0.20060 & 0.24308 & 0.29952 & 0.37408 \\
1.3 & 0.12207 & 0.14721 & 0.18223 & 0.22954 & 0.29291 & 0.37763 \\
1.4 & 0.08847 & 0.11027 & 0.14061 & 0.18204 & 0.23832 & 0.31473
\end{tabular}


$i=3$

\begin{tabular}{|c|c|c|c|c|c|c|}
\hline$\eta$ & $\mathrm{Co3}$ & $c_{13}$ & $\mathrm{C}_{23}$ & $c_{33}$ & $c_{43}$ & $\mathrm{C}_{53}$ \\
\hline 0.1 & 0.05449 & 0.01392 & 0.00916 & 0.00621 & 0.00522 & 0.00502 \\
\hline $0 . \hat{2}$ & 0.10613 & 0.03772 & 0.01954 & 0.01349 & 0.01137 & 0.01095 \\
\hline 0.3 & 0.13218 & 0.05625 & 0.03192 & 0.02283 & 0.01947 & 0.01581 \\
\hline 0.4 & 0.14803 & 0.07434 & 0.04665 & 0.03512 & 0.03060 & 0.02980 \\
\hline 0.5 & 0.15715 & 0.09175 & 0.06374 & 0.05099 & 0.04588 & 0.04535 \\
\hline a.j & 0.15169 & 0.10816 & 0.08290 & 0.07081 & 0.06630 & 0.06700 \\
\hline 0.7 & 0.15292 & 0.12312 & 0.10346 & 0.09446 & 0.09251 & 0.09620 \\
\hline 0.3 & 0.15142 & 0.13602 & 0.12443 & 0.12122 & 0.12452 & 0.13387 \\
\hline 2.9 & 0.15739 & 0.24601 & 0.14431 & 0.14955 & 0.15120 & 0.17975 \\
\hline 1.0 & 0.15049 & 0.15194 & 0.16100 & 0.17676 & 0.19975 & 0.23135 \\
\hline 1.1 & 0.14005 & 0.15223 & 0.17164 & 0.19871 & 0.23492 & 0.28272 \\
\hline 1.2 & 0.12512 & 0.14479 & 0.17235 & 0.20926 & 0.25802 & 0.32221 \\
\hline 1.3 & 0.10412 & 0.12681 & 0.15794 & 0.19976 & 0.25563 & 0.33023 \\
\hline 1.4 & 0.07502 & 0.09456 & 0.12151 & 0.15820 & 0.20802 & 0.27569 \\
\hline \multicolumn{7}{|c|}{$i=4$} \\
\hline$\eta$ & $\mathrm{CO}_{4}$ & $c_{14}$ & $C_{24}$ & $c_{34}$ & $\mathrm{C}_{44}$ & $\mathrm{C}_{54}$ \\
\hline 3.1 & 0.05412 & 0.01342 & 0.00850 & 0.00533 & 0.00405 & 0.00346 \\
\hline 3.2 & 0.10531 & 0.03663 & 0.01810 & $0.0115 ? 7$ & 0.00882 & 0.00755 \\
\hline 0.3 & 0.13077 & 0.05438 & 0.02944 & 0.01953 & 0.01508 & 0.01296 \\
\hline 3.4 & 0.14578 & 0.07136 & 0.04270 & 0.02987 & 0.02362 & 0.02049 \\
\hline 0.5 & 0.15368 & 0.08717 & 0.05767 & 0.04292 & 0.03514 & 0.03104 \\
\hline 0.6 & 0.15646 & 0.10124 & 0.07372 & 0.05863 & 0.05009 & 0.04540 \\
\hline 0.7 & 0.15512 & 0.11281 & 0.08980 & 0.07631 & 0.06836 & 0.06401 \\
\hline 0.3 & 0.14994 & 0.12081 & 0.10427 & 0.09445 & 0.08889 & 0.08638 \\
\hline 0.9 & 0.14057 & 0.12377 & 0.11483 & 0.11041 & 0.10912 & 0.11032 \\
\hline 1.0 & 0.12610 & 0.11969 & 0.11828 & 0.12003 & 0.12427 & 0.13074 \\
\hline 1.1 & 0.10502 & 0.10587 & 0.11021 & 0.11714 & 0.12640 & 0.13802 \\
\hline 1.2 & 0.07513 & 0.07869 & 0.08476 & 0.09295 & 0.10326 & 0.11587 \\
\hline
\end{tabular}




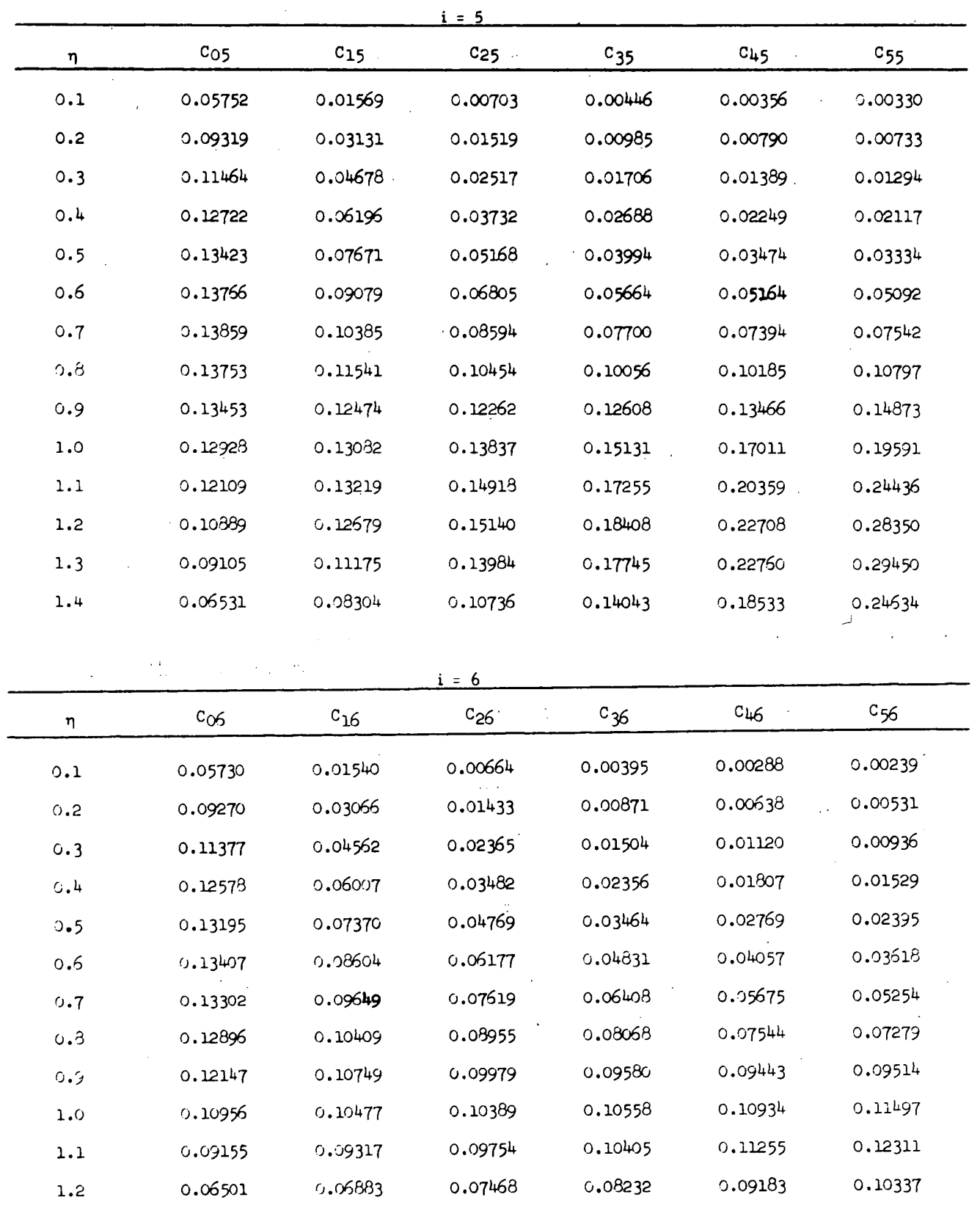




\begin{tabular}{lllllll}
\hline$\eta$ & $c_{07}$ & $c_{17}$ & $c_{27}$ & $c_{37}$ & $c_{47}$ & $c_{57}$ \\
\hline 0.1 & 0.05198 & 0.01320 & 0.00536 & 0.00302 & 0.00212 & 0.00171 \\
0.2 & 0.08296 & 0.02630 & 0.01169 & 0.00678 & 0.00479 & 0.00387 \\
0.3 & 0.10074 & 0.03920 & 0.01956 & 0.01197 & 0.00861 & 0.00700 \\
0.4 & 0.11057 & 0.05174 & 0.02917 & 0.01915 & 0.01428 & 0.01180 \\
0.5 & 0.11548 & 0.06368 & 0.04043 & 0.02873 & 0.02247 & 0.01905 \\
0.6 & 0.11714 & 0.07468 & 0.05296 & 0.04080 & 0.03373 & 0.02962 \\
0.7 & 0.11630 & 0.08418 & 0.06601 & 0.05500 & 0.04821 & 0.04416 \\
0.3 & 0.11306 & 0.09138 & 0.07840 & 0.07029 & 0.06533 & 0.06263 \\
0.9 & 0.10696 & 0.09503 & 0.08826 & 0.08460 & 0.08318 & 0.08354 \\
1.0 & 0.09696 & 0.09329 & 0.09276 & 0.09437 & 0.09774 & 0.10272 \\
1.1 & 0.08132 & 0.08339 & 0.08770 & 0.09384 & 0.10172 & 0.11141 \\
1.2 & 0.05739 & 0.06130 & 0.06691 & 0.07409 & 0.08292 & 0.09361
\end{tabular}

\begin{tabular}{ccccccc}
\hline$\eta$ & $c_{08}$ & $c_{18}$ & $c_{28}$ & $c_{38}$ & $c_{48}$ & $c_{58}$ \\
\hline 0.1 & 0.05180 & 0.01298 & 0.00511 & 0.00273 & 0.00178 & 0.00132 \\
0.2 & 0.03253 & 0.02581 & 0.01112 & 0.00613 & 0.00403 & 0.00299 \\
0.3 & 0.09997 & 0.03831 & 0.01853 & 0.01078 & 0.00724 & 0.00541 \\
0.4 & 0.10925 & 0.05022 & 0.02742 & 0.01713 & 0.01194 & 0.00909 \\
0.5 & 0.11330 & 0.05117 & 0.03754 & 0.02538 & 0.01860 & 0.01457 \\
0.6 & 0.11359 & 0.07059 & 0.04824 & 0.03535 & 0.02742 & 0.02232 \\
0.7 & 0.11059 & 0.07760 & 0.05841 & 0.04621 & 0.03804 & 0.03238 \\
0.8 & 0.10394 & 0.08086 & 0.06626 & 0.05626 & 0.04909 & 0.04382 \\
0.9 & 0.09252 & 0.07839 & 0.06905 & 0.06240 & 0.05748 & 0.05378 \\
1.0 & 0.07430 & 0.06717 & 0.06262 & 0.05953 & 0.05743 & 0.05602
\end{tabular}


$i=9$

\begin{tabular}{lllllll}
\hline$\eta$ & $c_{09}$ & $c_{19}$ & $c_{29}$ & $c_{39}$ & $c_{49}$ & $c_{59}$ \\
\hline 0.1 & 0.04758 & 0.01138 & 0.00426 & 0.00219 & 0.00138 & 0.00100 \\
0.2 & 0.07489 & 0.02265 & 0.00939 & 0.00498 & 0.00318 & 0.00230 \\
0.3 & 0.08988 & 0.03367 & 0.01583 & 0.00894 & 0.00585 & 0.00428 \\
0.4 & 0.09764 & 0.04426 & 0.02370 & 0.01449 & 0.00989 & 0.00739 \\
0.5 & 0.10095 & 0.05421 & 0.03279 & 0.02186 & 0.01578 & 0.01219 \\
0.6 & 0.10116 & 0.06272 & 0.04257 & 0.03092 & 0.02375 & 0.01915 \\
0.7 & 0.09865 & 0.06932 & 0.05205 & 0.04100 & 0.03357 & 0.02841 \\
0.8 & 0.09303 & 0.07268 & 0.05960 & 0.05055 & 0.04402 & 0.03920 \\
0.9 & 0.08314 & 0.07088 & 0.06262 & 0.05667 & 0.05224 & 0.04887 \\
1.0 & 0.06685 & 0.06090 & 0.05704 & 0.05442 & 0.05262 & 0.05141
\end{tabular}

$i=10$

\begin{tabular}{lllllll}
\hline$\eta$ & $c_{0,10}$ & $c_{1,10}$ & $c_{2,10}$ & $c_{3,10}$ & $c_{4,10}$ & $c_{5,10}$ \\
\hline 0.1 & 0.04398 & 0.01000 & 0.00350 & 0.00166 & 0.00096 & 0.00064 \\
0.2 & 0.06834 & 0.01987 & 0.00778 & 0.00384 & 0.00225 & 0.00150 \\
0.3 & 0.08115 & 0.02948 & 0.01320 & 0.00700 & 0.00424 & 0.00285 \\
0.4 & 0.08732 & 0.03858 & 0.01982 & 0.01145 & 0.00730 & 0.00503 \\
0.5 & 0.08936 & 0.04679 & 0.02732 & 0.01731 & 0.01174 & 0.00843 \\
0.6 & 0.08831 & 0.05347 & 0.03502 & 0.02428 & 0.01762 & 0.01330 \\
0.7 & 0.08415 & 0.05759 & 0.04170 & 0.03140 & 0.02438 & 0.01942 \\
0.8 & 0.07590 & 0.05742 & 0.04525 & 0.03665 & 0.03030 & 0.02547 \\
0.9 & 0.06146 & 0.05016 & 0.04224 & 0.03630 & 0.03165 & 0.02792
\end{tabular}




\section{DOCUMENT CONTROL DATA - R \& D}

(Security classification of title, body of abstract and indexing annotation must be entered when the overall report is classified) 1. ORIGINATING ACTIVITY (Corporate author) 2E. REPORT SECURITY CLASSIFICATION

U.S. Army Cold Regions Research and

Engineering Laboratory, Hanover, N. H. Unclassified

2b. GROUP

3. REPORT TITLE

A NEW SOLUTION .OF THE BOUNDARY LAYER EQUATION AND ITS APPLICATION

4. DESCRIPTIVE NOTES (TYPe of roport and inclusive dates)

Research Report

5. AU THOR(S) (Firat name, middio initial, last namo)

Fuat Odar

\begin{tabular}{|c|c|c|}
\hline $\begin{array}{l}\text { 6. REPORT DATE } \\
\text { August } 1967\end{array}$ & $\begin{array}{l}\text { 7a. TOTAL NO. OF PAGES } \\
29\end{array}$ & $\begin{array}{c}\text { 7b. NO. OF REFS } \\
7\end{array}$ \\
\hline $\begin{array}{l}\text { B. CONTRACT OR GRANT NO. } \\
\text { b. PROJECT NO. }\end{array}$ & $\begin{array}{l}\text { 9a. ORIGINATOR'S REPOR } \\
\text { Research Repo }\end{array}$ & 7 \\
\hline $\begin{array}{l}\text { c. DA Task } 1 \mathrm{VO} 14501 \mathrm{~B} 52 \mathrm{AO} 02 \\
\text { d. }\end{array}$ & $\begin{array}{l}\text { 9b. OTHER REPORT NO(S) } \\
\text { this roport) }\end{array}$ & hor numbere that may be aselened \\
\hline
\end{tabular}

Distribution of this document is unlimited.

11. SUPPLEMENT.ARY NOTES

12. SPONSORING MILITARY ACTIVITY

U.S. Army Cold Regions Research, and Engineering Laboratory, Hanover, N.H.

13. ABSTRACT

Solutions of the boundary layer equation for an unsteady flow have previously been obtained for only a few boundary conditions such as those which exist in suddenly accelerated or uniformly accelerating flows. In this pape $r$ a general solution using the method of successive approximations for an arbitrarily accelerating flow is presented. The solution, which is expressed in an integral form including the acceleration as a chosen function of time, is valid for both two-dimensional and axially symmetrical flow's. An example is presented in which the variation of velocity outside of the boundary layer is a fourth degree polynomial in time multiplied by a function depending on shape of object. 
Unclassified

Security Classification

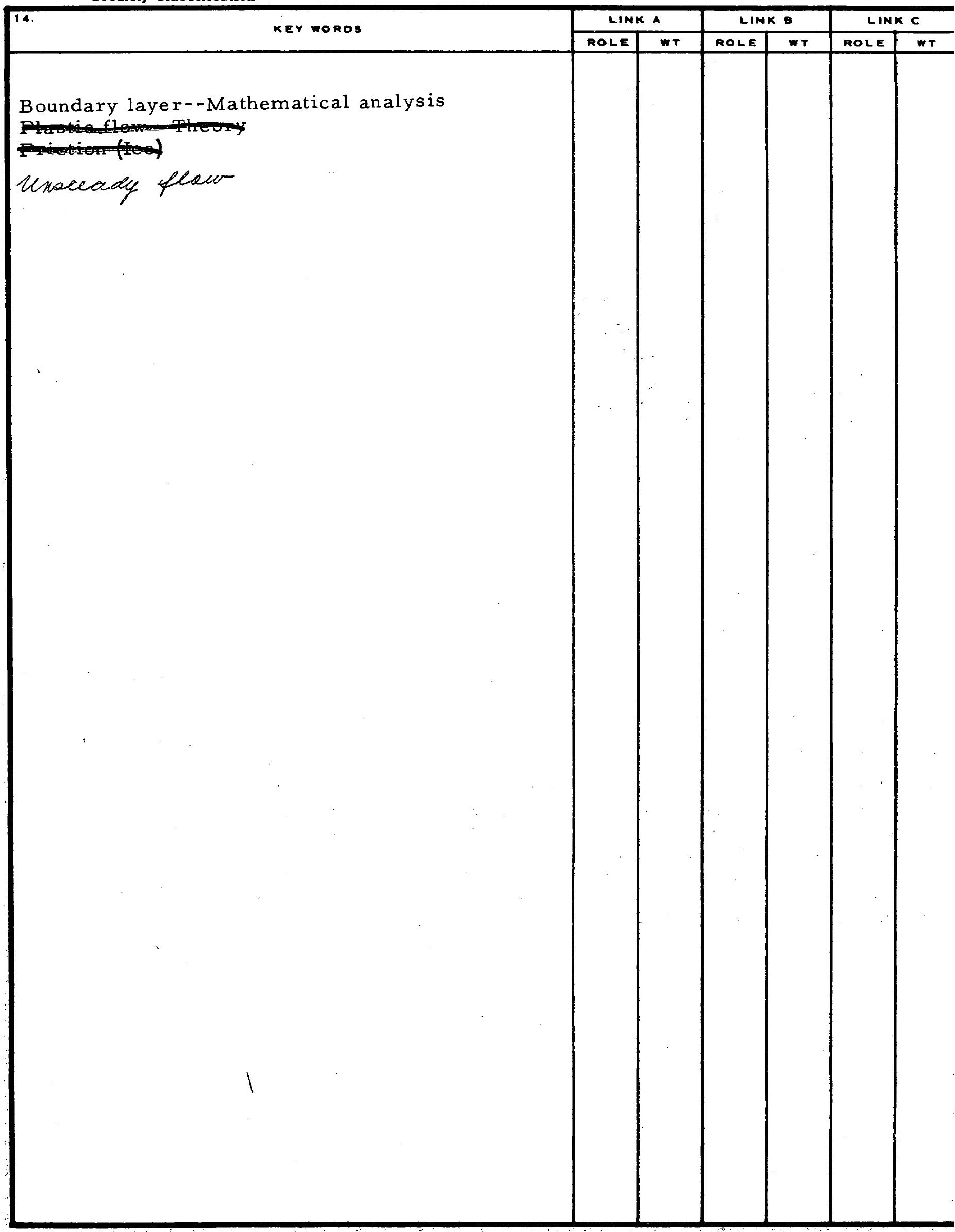

Unclassified

Security Classification 